\title{
Differential Effects of Age on Neuromuscular Transmission in Partially Denervated Mouse Muscle
}

\author{
Jane M. Jacob and Norman Robbins \\ Center for Neurosciences, Case Western Reserve University, Cleveland, Ohio 44106
}

The response of the neuromuscular junction to expansion of the motor unit after partial denervation (section of L5 root) was compared in soleus muscles from young (5-8 month) and old (25-30 month) mice. The object was to determine the relative capacity of young and old motor neurons to adapt to an enlarged functional field of innervation, and to delineate physiological parameters that are compromised under these conditions. Neuromuscular function was studied at 30 , 60 , and $120 \mathrm{~d}$ after partial denervation. The initial (18-23) and postoperative number (5-8) of motor units was the same in both age groups. Twitch strength declined in proportion to loss of motor units at $30 \mathrm{~d}$ but returned completely (young) or nearly completely (old) by $60 \mathrm{~d}$. In old but not young muscle, the safety factor (assayed by twitch depression in low calcium) was decreased even before functional sprouting had occurred, indicating a reduced safety factor in nondenervated junctions. The proportion of fibers with "long" latencies (delay between stimulation and endplate potential) increased transiently (at $\mathbf{3 0} \mathrm{d}$ ) in young muscle but persisted without recovery at $120 \mathrm{~d}$ in regenerated junctions in old muscle.

After partial denervation, decline in miniature endplate potential (mepp) amplitude, in mepp frequency, and in estimated quantal content of evoked release was relatively more pronounced in old than in young mice, and in the case of mepp amplitude and frequency, more persistent. Mepp amplitude was also decreased in presumed nondenervated junctions of old muscles.

Thus, in contrast to results in young mice, forced expansion of the motor unit in old mice led to greater relative physiological deficits in both regenerated and nondenervated junctions of the expanded motor unit, and a persistent increase in latency of newly regenerated junctions.

After partial denervation of mammalian skeletal muscle, the remaining motor axons sprout to supply an expanded field of innervation (Brown and Ironton, 1978a). In newborn and young animals, synapses in the enlarged motor unit after partial denervation show evidence of reduced efficacy, i.e., increased susceptibility to block by curare, rapid fatigue, and decreased twitch/ tetanus ratios (Brown et al., 1976; Thompson and Jansen, 1977;

\footnotetext{
Received July 27, 1989; revised Dec. 11, 1989; accepted Dec. 13, 1989.

This work was supported by NIH grants AG00795, AG08886, and T32-AG00105 and the Muscular Dystrophy Association. We wish to thank Ms. Gretchen Bowling and Mrs. Jane Hill for their able technical assistance.

Correspondence should be addressed to Dr. Jane M. Jacob at her present address: Neural Regeneration Center-151 W, Veterans Administration Medical Center, 10701 East Boulevard, Cleveland, OH 44106.

Copyright (C) 1990 Society for Neuroscience $0270-6474 / 90 / 051522-08 \$ 02.00 / 0$
}

Brown and Ironton, 1978a). In young mature mice, expansion of the motor unit results in 2 populations of nerve terminalsthose that resemble the original, or parent, nerve terminals and those with the characteristics of sprouted nerve terminals, including a reduced safety factor (Rochel and Robbins, 1988). The latter result suggests a limitation in either growth or maintenance when the motor unit is forced to expand.

The study of partial denervation in aging animals can further elucidate both general issues of synaptic maintenance as well as specific questions related to aging. First, partial denervation in aged animals can be used as a perturbation to study the physiological adaptations to and consequences of limited synaptic maintenance. Indeed, there is evidence that maintenance of motor nerve terminals in the intact aged rodent may be marginal, e.g., decreased numbers of synaptic vesicles and mitochondria (Fahim and Robbins, 1982) and reduced axonal transport (McMartin and O'Connor, 1979; Komiya, 1980). Thus, the sprouting response to partial denervation may place demands on the cell body for increased synthesis or transport of structural proteins and transmitter-related components which exceed the capacity of the aging motor neuron. A study of synaptic physiology under these circumstances would determine those parameters that are sensitive to a deficit in maintenance. In addition, this analysis would determine whether under circumstances of presumed limited supply by axonal transport, original nondenervated synapses of an expanded motor unit would stay intact or would exhibit changes indicative of a redistribution of materials between original and sprouted junctions. Indeed, experimental reduction of motor unit size reduces transmitter release at the remaining junctions (cf. Herrera and Grinnell, 1981).

Throughout the aging nervous system, spontaneous cell death and reactive sprouting to spontaneous partial denervation has been described (Curcio et al., 1982; Scheff et al., 1984; McWilliams, 1988), but there have been no studies in which the cellular synaptic physiology has been analyzed under these circumstances. Partial denervation in the neuromuscular junction offers a simplified system in which to study these problems. In addition, there are age-related neuromuscular diseases involving cell loss and sprouting, such as amyotrophic lateral sclerosis and postpolio syndrome, in which functional deficits may be elucidated by the animal model analyzed here. In this paper, we compare the physiological effects of partial denervation in young and old mice.

\section{Materials and Methods}

Animals. Male CBF-1 (Balb/cNNiaa $\times$ C57BL/6Niaa) mice (Charles River Laboratories), all at least $35 \mathrm{gm}$ body weight, were used at ages 5-8 months (young) and 25-30 months (old). Mice with evidence of 
hindlimb ankylosis or gross organ pathology (upon autopsy) were excluded (Fahim and Robbins, 1982). Mice were housed in individual plastic cages with filter hoods and were fed standard laboratory chow ad lihitum.

Partial denervation. Partial denervation of the soleus muscle by transection of the L5 spinal nerve was carried out under Diabutol (Diamond Laboratories, Inc.) anesthesia [60 mg/kg, intraperitoneally (i.p.)] as described elsewhere (Rochel and Robbins, 1988). At various times after operation, mice were reanesthetized with methoxyfluorane (PitmanMoore), and the soleus muscle with a $4 \mathrm{~mm}$ length of motor nerve was removed for study.

Reinnervation by the transected root was prevented by redirecting the distal cut end of the spinal nerve into the surrounding musculature of the back. Several findings indicate that L5 motor units never regenrated back to soleus muscle. First, in several animals, a complete dissection of the roots weeks to months after operation showed no evidence of $\mathrm{L} 5$ regeneration. Second, in acute experiments, stimulation of the L4 spinal root produced twitch tension $\sim 25 \%$ of that obtained from soleus muscle nerve stimulation, which is similar to the proportion of motor axons found to remain 30-120 d after operation. Third, there was no increase in the number of remaining motor units between 30 and 120 d after operation (see Results).

\section{Physiology}

Isometric twitch tension. In brief (see Rochel and Robbins, 1988, for details), the distal tendon of the soleus muscle was pinned in a dish containing oxygenated normal Krebs solution (135 mm NaCl, $1 \mathrm{~mm}$ $\mathrm{MgSO}_{4}, 11 \mathrm{~mm}$ glucose, $1 \mathrm{~mm} \mathrm{Na} \mathrm{PO}_{4}, 15 \mathrm{~mm} \mathrm{NaHCO}, 2.5 \mathrm{~mm} \mathrm{Ca}-$ gluconate and glass-distilled water, $\mathrm{pH} 7.4$ ) at room temperature (22$25^{\circ} \mathrm{C}$. Indirect and direct twitch tensions were measured in normal Krebs solution, after $25 \mathrm{~min}$ in a solution containing a lower $\mathrm{Ca} / \mathrm{Mg}$ ratio $(0.5 \mathrm{~mm}(\mathrm{a} / 9 \mathrm{~mm} \mathrm{Mg})$, and again $30 \mathrm{~min}$ after recovery in normal solution. The ratio of indirect twitch tension in the altered Krebs solution to that in normal Krebs solution was used as an estimate of summed safety factor of all junctions within the muscle (Grinnell and Herrera, 1980)

Hotor unit number. The number of motor units in each muscle was determined by slowly incrementing the voltage applied to the motor nerve, with constant, relatively short $(60 \mu \mathrm{sec})$ pulse durations, as described in Rochel and Robbins (1988). The process was repeated twice per muscle and the results were averaged. In repeated counts of individual motor units by incrementing the stimulating voltage, the estimated number of presumed motor units did not vary more than $10 \%$. Furthermore, as reported below, the numbers of motor units remaining after partial denervation were consistently in a narrow range. Most important, the fraction of motor units left after partial denervation, determined by this method, corresponded well with the fraction of wwitch tension remaining shortly after partial denervation, before functional sprouting ensued. Finally, in immunocytochemical studies, the average number of motor axons per nerve accumulating synaptophysin $3 \mathrm{hr}$ after soleus nerve crush was 21 , i.e., similar to that found using the physiological method of incremental current (Robbins and Ivan, unpublished observations).

Intracellular recording. The soleus muscle was dissected from the animal and placed in a $10 \mathrm{ml}$ Perspex chamber perfused by oxygenated $\left.195 \% \mathrm{O} .5 \% \mathrm{CO}_{2}\right) \mathrm{Krebs}$ solution. All intracellular recordings were made in low $\mathrm{Ca}$ \%/high $\mathrm{Mg}^{2} \cdot(0.4 \mathrm{~mm} \mathrm{Ca} / 2.5 \mathrm{~mm} \mathrm{Mg}) \mathrm{Krebs}$ solution as described elsewhere (Kelly and Robbins, 1983). Briefly, muscle fibers were impaled, and fibers were selected in which the rise time of miniature endplate potentials (mepps) was less than $0.6 \mathrm{msec}$. Amplified signals were digitized, corrected, and analyzed with a Northstar computer. In general. 100 mepps were recorded from control muscle fibers whereas 50 mepps were recorded from partially denervated muscles, in which mepp frequency was often low. "Giant" mepps were excluded (Kelly and Robbins, 1983). Endplate potentials (epps) evoked by nerve stimulation at $1 \mathrm{~Hz}$ and mepp amplitudes were measured from preparations in Krebs saline solution with reduced $\mathrm{Ca} /$ raised $\mathrm{Mg}(0.4 \mathrm{~mm} \mathrm{Ca} / 2.5$ $\mathrm{mm} \mathrm{Mg}$ ) to prevent muscle contraction during stimulation. The quantal content of each junction was estimated using the methods of coefficient of variation (1/CV) and of "failures" [ln(\#)vents/\#failures); Del Castillo and Katz, 1954].

Latency (the delay between stimulation and epp) was also analyzed from digitized data. The variability in successive groups of recordings from the same fiber was less than $5 \%$.

Statistics. Unless indicated otherwise, all statements of significance

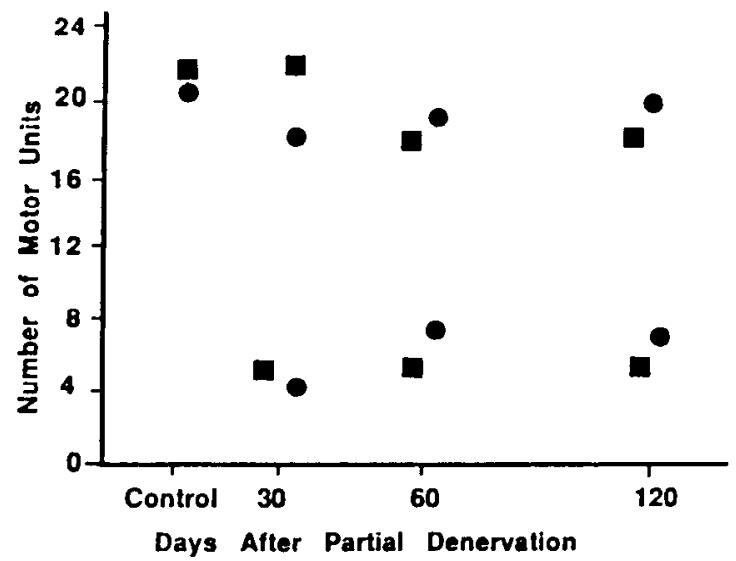

Figure 1. The number of motor units in young (squares) and old (circles) muscle before (higher values, 18-23 motor units) and after (lower values, 3-8 motor units) partial denervation. Data are means of 4-11 young and $3-11$ old mice.

are based on $p$-values $\leq 0.05$, obtained by either Student's $/$ test or the Mann-Whitney test. Percentage data were first converted to logarithms before statistical analysis

\section{Results}

Motor unit number. The number of soleus motor units was similar in all control muscles regardless of age. The mean number of motor units was between 18 and 23 (range of individual values, 15-30) in young and old unoperated control muscles as well as in young and old contralateral control muscles (Fig. 1). No significant differences were found between these groups. In both young and old mice, an average of 4-8 motor units per muscle remained from 30 to $120 \mathrm{~d}$ after transection of the L5 spinal nerve; i.e., partial denervation produced a persistent loss of $\sim 70 \%$ of motor innervation at both ages.

Isometric twitch tension. The ratio of indirect to direct twitch tension showed no major age difference at any time after operation (Fig. 2A). At 10 and $30 \mathrm{~d}$ after partial denervation, the ratio of indirect to direct tension in both young and old muscle was approximately $30-40 \%$ of the control value (Fig. 2.1)-a finding consistent with the $\sim 70 \%$ loss of motor units (see above) and indicative of no functional collateral sprouting. Similar results (not shown) were obtained at $10 \mathrm{~d}$, an indication that the partial denervation was effective and that no damage to the L4 spinal root had occurred. At $60 \mathrm{~d}$ the twitch had returned to control values in young operated muscles and was only slightly reduced in old operated muscles. At both ages, the indirect/ direct ratio was at control levels by $120 \mathrm{~d}$. Absolute values of indirect twitch tension varied between groups of animals cven in controls, but the pattern of recovery was similar to that of the indirect/direct twitch ratio.

Measurements of indirect tetanic tension were consistent with those obtained with single twitches, showing no change in the ratio of plateau tetanic tension to twitch tension in control muscles (ratio: 3.1 young, 3.4 old, $n=2$ muscles) or at $60 \mathrm{~d}$ after partial denervation (ratio: 3.0 young. 2.8 old. $n=2$ ). Thus. normal tetanic function was attained by $60 \mathrm{~d}$ after operation and the single twitch data were proportional to those obtained through tetani.

Assay of safety factor. In low $\mathrm{Ca} / \mathrm{high} \mathrm{Mg} \mathrm{Krebs}$ solution. contractile strength of mouse muscle is unaffected but transmitter release is reduced (Banker et al., 1983), and only those 
Figure 2. A, Mean indirect/direct twitch tension in normal Krebs solution in young (squares) and old (circles) muscle at indicated times after partial denervation. Logarithms were used to calculate the SEM; therefore, error bars are of unequal lengths on either side of the mean. At $10 \mathrm{~d}, n=2$; at other times, data are means of 3-9 muscles. $B$, Indirect twitch tension in low $\mathrm{Ca}^{2+} / \mathrm{high}$ $\mathrm{Mg}^{2}$ Krebs solution as a percentage of that obtained in normal Krebs, before and after partial denervation in young (squares) and old (circles) muscle. Logarithms were used to calculate the SEM. Data points with standard error bars are from 4-9 muscles. Asterisks, Significantly different from control of the same age group.
A.

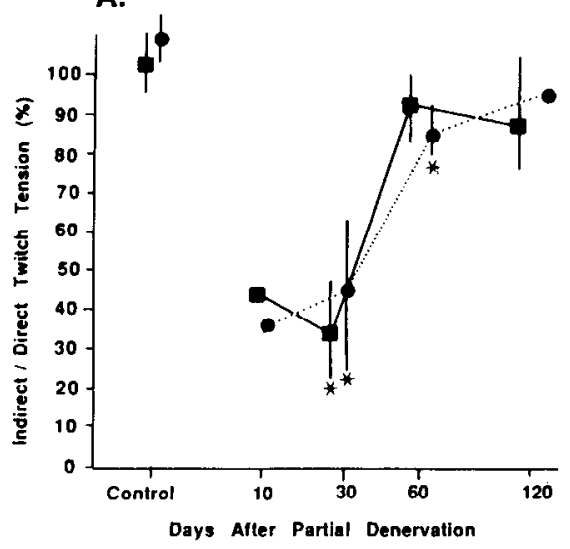

B.

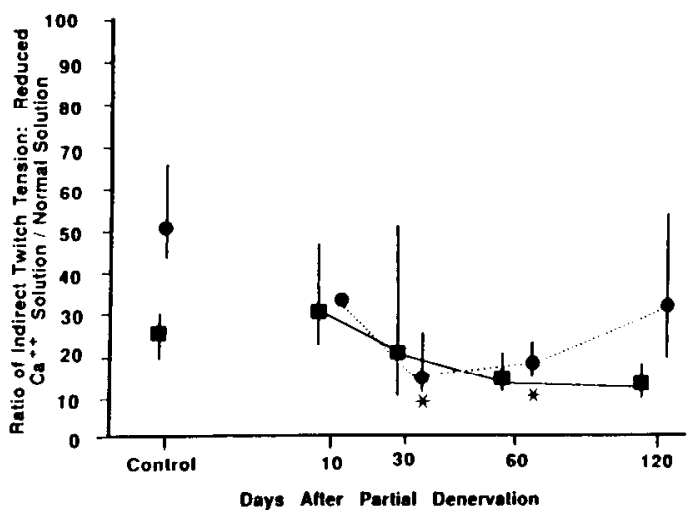

nerve terminals with a sufficiently high safety factor reach threshold (Grinnell and Herrera, 1980). Thus, indirect twitch tension in low $\mathrm{Ca} /$ high $\mathrm{Mg}$ Krebs solution, as a percentage of that obtained in standard Krebs solution, supplies an estimate of the safety factor of transmission (e.g., Grinnell and Herrera, 1980; Banker et al., 1983). In young control muscle, the twitch in low $\mathrm{Ca} /$ high $\mathrm{Mg}$ solution was $25 \%$ of that in normal Krebs solution (Fig. $2 B$ ). At boin 10 and $30 \mathrm{~d}$ after partial denervation in young mice, the percentage remained the same; i.e., the remaining functional junctions had the same safety factor as the original motor axons innervating the muscle. By 60 and $120 \mathrm{~d}$, functional sprouting had occurred (see Fig. $2 A$ ) and concurrently there was a small decrease in the overall safety factor. Apparently, sprouted junctions with lower safety factors (see also below) now contributed to the total twitch tension of the muscle in normal Krebs, but fell below threshold in low $\mathrm{Ca} /$ high $\mathrm{Mg}$ Krebs.

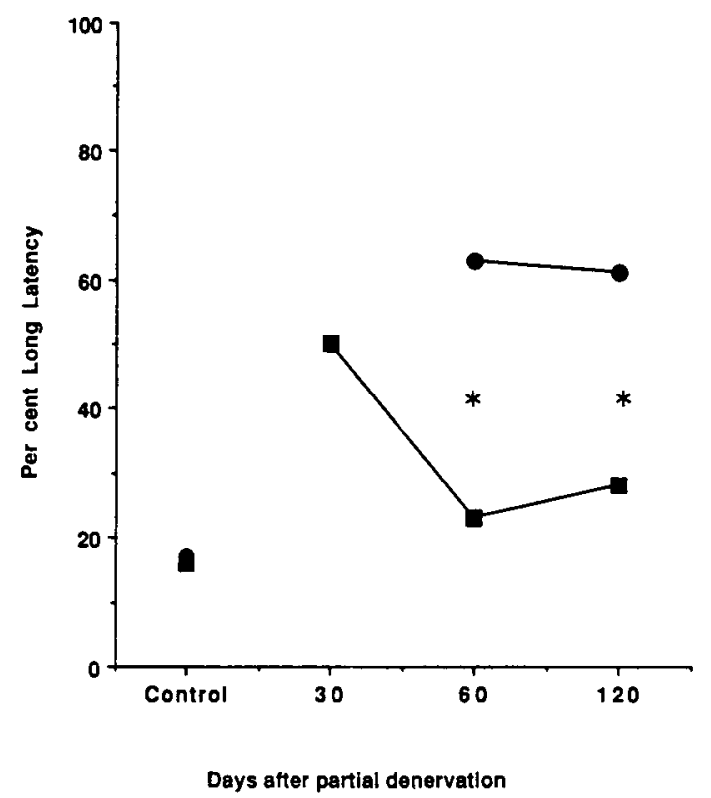

Figure 3. Percentage of fibers with latencies $\geq 1.3 \mathrm{msec}$ at indicated times after partial denervation in young (squares) and old (circles) mice. Data points represent mean of 78-82 fibers in control and 16-29 fibers in experimental muscle. Asterisks, Significant differences between young and old muscles.
In old control muscle, tension was reduced by only $50 \%$ in low $\mathrm{Ca}$ /high $\mathrm{Mg}$ Krebs solution (Fig. $2 B$ ), as expected from other studies (Banker et al., 1983). However, by 10 and $30 \mathrm{~d}$ after partial denervation, the safety factor was substantially reduced (Fig. $2 B$ ) even though no functional reinnervation had occurred (Fig. 2A). This result indicates that nondenervated junctions remaining at 10 and $30 \mathrm{~d}$ after partial denervation had a lower safety factor.

Latency. Latency, defined as the delay between nerve stimulation and the foot of the epp, ranged from 0.5 to $1.7 \mathrm{msec}$ in control young and old muscles. "Long latencies," defined as $\geq 1.3 \mathrm{msec}$, were found in less than $20 \%$ of control muscles in either young or old mice (Fig. 3). Sprouted junctions supplied by thin axon branches would be expected to have long latencies. Indeed, after partial denervation in young mice, an increase in the percentage of fibers with long latencies was seen at $30 \mathrm{~d}$ (Fig. 3 ), with a median long latency of $1.65 \mathrm{msec}$ (range 1.3-2.5 msec). These long latencies were generally in fibers with relatively lower mepp frequency and quantal content (see below). Unfortunately, in $30 \mathrm{~d}$ operated old animals, muscle fibers were delicate and difficult to penetrate, partly due to the prevalence of fibrillation. Since the sample obtained was small and probably nonrepresentative, data from this time point were not included. At 60 or $120 \mathrm{~d}$, latencies $\geq 1.3 \mathrm{msec}$ were found in $60-65 \%$ of the fibers in old operated muscle, whereas in young muscle, neither this percentage nor the median or range of long latencies was significantly greater than that of control muscle. Since latency recovered in most sprouted fibers in young muscle, a short latency could no longer be used to distinguish sprouted and original terminals. However, in old muscle, with a persistent high proportion of long-latency fibers up to $120 \mathrm{~d}$, latency still identified sprouted terminals at both 60 and $120 \mathrm{~d}$ after operation. Nonetheless, median long-latency values at $120 \mathrm{~d}(1.45 \mathrm{msec}$, range 1.3-3.2) showed a trend toward lower values compared to those at $60 \mathrm{~d}$ (median $1.8 \mathrm{msec}$, range $1.3-3.0 \mathrm{msec}$ ).

Miniature endplate potential amplitude and frequency. Mepp amplitude was slightly smaller in young than in old unoperated control muscle (Fig. 4). In young mice, partial denervation resulted in no significant change in mean mepp amplitude at 30 $\mathrm{d}$ but an apparent bimodal distribution of amplitudes (Fig. 4) and a higher percentage of long-latency fibers (Fig. 4), indicating that the surface recordings may have selected for a higher proportion of early sprouted fibers than in the whole muscle. In the latter, twitch measurements did not indicate substantial 


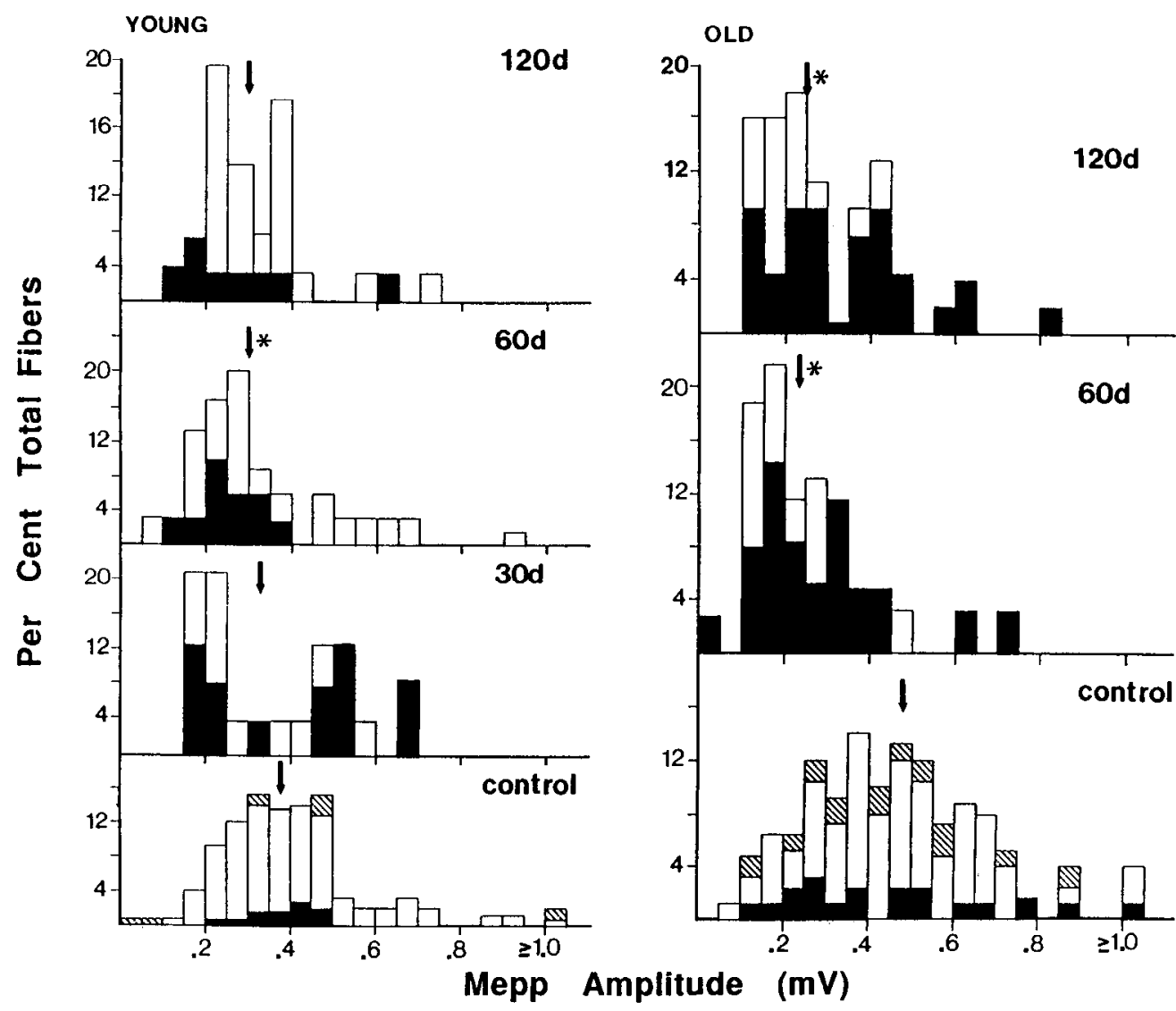

Figure 4. Amplitude histograms of mepp amplitude in young $(l e f t)$ and old (right) mice at indicated times after partial denervation. Data for each histogram were derived from 13-55 fibers in 3-7 muscles. Control data were pooled from the contralateral control and unoperated muscles $(n=102$ or 130 fibers from 17 and 19 young and old muscles, respectively). In old mice, data at $30 \mathrm{~d}$ are omitted (see text). Arrows indicate median mepp amplitudes. Open bars represent short-latency fibers, filled bars represent long-latency fibers, and hatched bars are fibers with undetermined latencies. Asterisks, $p \leq 0.05$, Mann-Whitney nonparametric test for difference from controls. functional sprouting. However, since at $30 \mathrm{~d}$ there was considerable variation between muscles, the inevitable sampling of intracellular recording at this critical time may not have reflected the status of the whole muscle. Also, reduced fiber diameter of newly reinnervated muscle may account for large-amplitude mepps due to increased input resistance. Given the small sample size $(n=23)$, the apparent appearance of a larger mode depended on only 4 additional fibers. At $60 \mathrm{~d}$ after partial denervation, mepp amplitude was reduced by $27 \%$ but by $120 \mathrm{~d}$ values were not significantly different from control (Fig. 4). At those times, the majority subpopulation of short-latency, presumably original ("parent") terminals or recovered sprouted terminal fibers showed mepps of normal amplitude (Fig. 4) while mepp amplitude in long-latency fibers was reduced by $40 \%$.

In old mice, partial denervation led to even greater relative diminution of overall mepp amplitudes at 60 and $120 \mathrm{~d}(53 \%$ and $47 \%$, respectively) than in young mice (Fig. 4). However, in old mice, mepp amplitudes in the "parent" (short-latency) fibers were also significantly less than that of contralateral control values (e.g., control, $0.47 \pm 0.03$, mean $\pm \mathrm{SE}$; operated, $0.23 \pm 0.02$ at $60 \mathrm{~d}$ ). Thus, with respect to mepp amplitude, nondenervated junctions were altered in old but not in young muscles.

Junctions in unoperated (control) young muscles showed median mepp frequencies similar to those of old mice (Fig. 5). At both ages, median frequency decreased at $60 \mathrm{~d}$ postdenervation. However, mepp frequency returned to control levels by $120 \mathrm{~d}$ in young but not in old mice (Fig. 5). At $30 \mathrm{~d}$ in young mice, and at 60 and $120 \mathrm{~d}$ in young and especially in old mice, mepp frequencies $<1 \mathrm{~Hz}$ were often associated with long latencies
(Fig. 5). In both young and old short-latency fibers, mepp frequencies returned to control values by $120 \mathrm{~d}$.

Quantal content. In partially denervated muscle, the apparent "unit" epp amplitude was frequently greater than mean mepp amplitude (e.g., Fig. 6). Therefore, the computation of quantal release $(m)$ by the direct method of Del Castillo and Katz (1954), where $m=$ (mean epp amplitude)/(mean mepp amplitude), was not appropriate. In addition, release statistics of junctions in mouse soleus, especially in old mice, do not necessarily follow Poisson distributions (Kelly and Robbins, 1987). Assuming that some other unit source besides mepps provided the quantum of release, $m$ was estimated by use of the CV (Del Castillo and Katz, 1954). Thus, the quantity $1 / C V^{2}$, where $C V$ is the coefficient of variation of epp amplitudes, was used as a first-order cstimatc of average quantal release (cf. Fig. 1 and results in Kelly and Robbins, 1987). A third method [ $m=\ln$ (\#)events/ \#failures); Del Castillo and Katz, 1954] yielded similar results.

Quantal content in control old muscles was higher than in young muscle, as previously reported (Banker et al., 1983). Furthermore, in young but not in old muscle, there was a definite association between lower quantal content and long latency. This finding may reflect a correlation between preterminal axon diameter and transmitter release, related perhaps to the correlation between smaller motor unit size and lower transmitter release (Grinnell and Trussell, 1980). At $30 \mathrm{~d}$ after partial denervation in young mice, overall median quantal content was essentially unchanged but was reduced at later times (Fig. 7 and Table 1). In old muscle, there was a larger relative reduction of quantal content at $60 \mathrm{~d}$ and little recovery by $120 \mathrm{~d}$ (Table 1), with the result mainly reflecting the low quantal content of the 
Figure 5. Histograms of mepp frequency $(\mathrm{Hz})$ in young and old mice at indicated times after partial denervation. Data were from 14-52 fibers in 37 muscles per time point. Other information as in Figure 4.

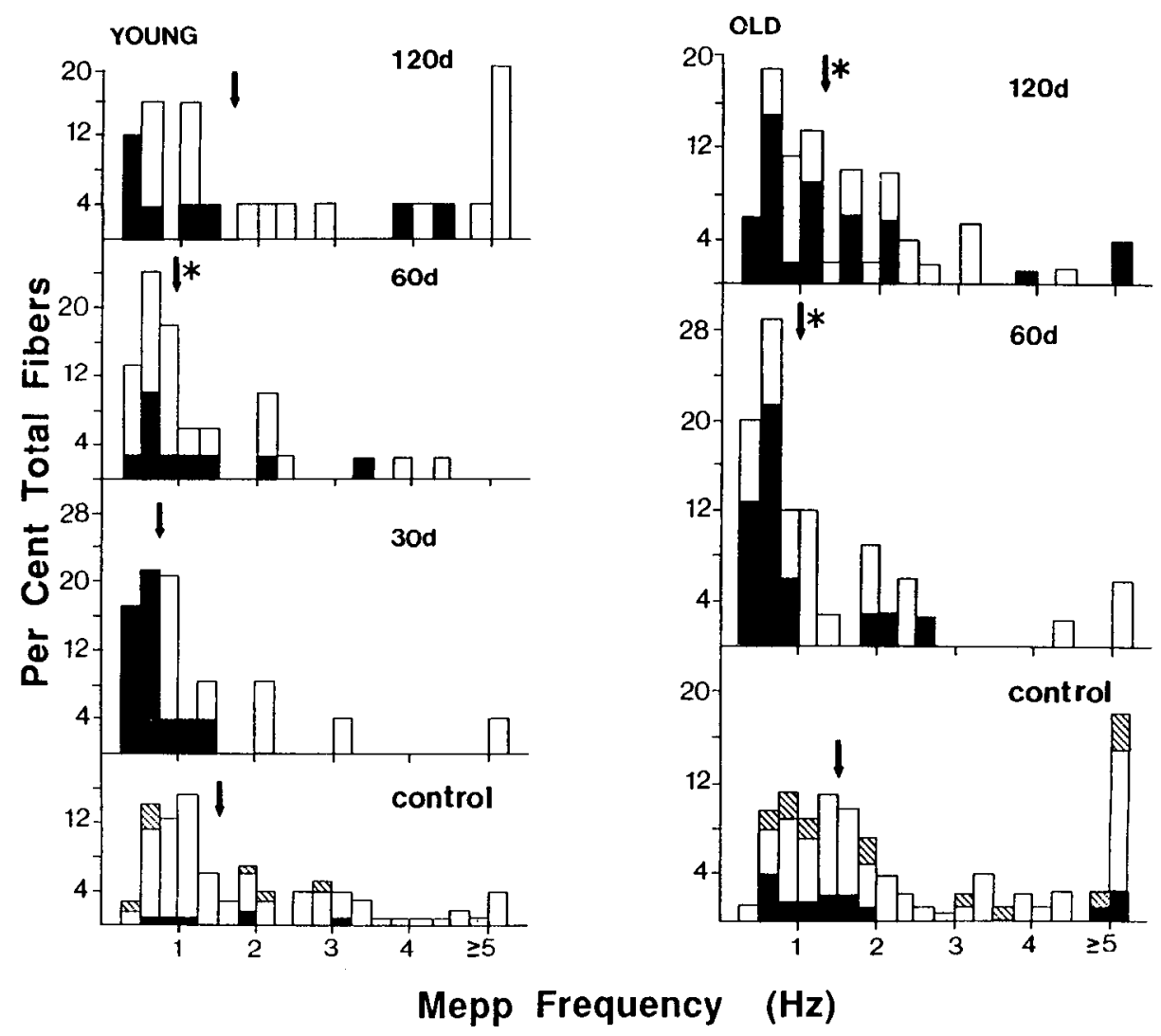

of recovery of twitch strength, as previously reported in young mice (see above). However, an assay of safety factor and intracellular recording revealed transient or persistent differential effects of age.

\section{Changes in spontaneous transmitter release after partial denervation}

The reduced mepp amplitude observed after partial denervation, which was also reported during nepromuscular development (Dennis, 1981) or recovery from botulinum toxin poisoning (Cull-Candy et al., 1976), may reflect immaturity of the release mechanism in regenerated nerve terminals. Possible mechanisms include small or less fully charged synaptic vesicles, or the unmasking of a preexisting population of small amplitude mepps which are present in a fraction of control muscle fibers (Kelly and Robbins, 1984). In partially denervated fibers, the unit mepp was often smaller than the unit epp, and in these cases, either multiple units were released simultaneously by nerve stimulation or a different population of vesicles was mobilized. Indeed, the reduced amplitude of spontaneous mepps was apparently not reflected in a reduced amplitude of the unit quantum released by nerve stimulation: in old muscle, where mepp amplitude showed the greatest decrease, the relative decline in mean epp amplitude after partial denervation paralleled the decline in quantal content, which would not be the case if the unit quantum of evoked release were smaller only because of reduced mepp amplitude. The proportionate reduction in epp amplitude and quantal content also indirectly indicates that acetylcholine sensitivity was intact, and therefore, that the decreased mepp size was not due to this mechanism. It is unlikely that reduced mepp amplitude was due to muscle fiber hyper- 


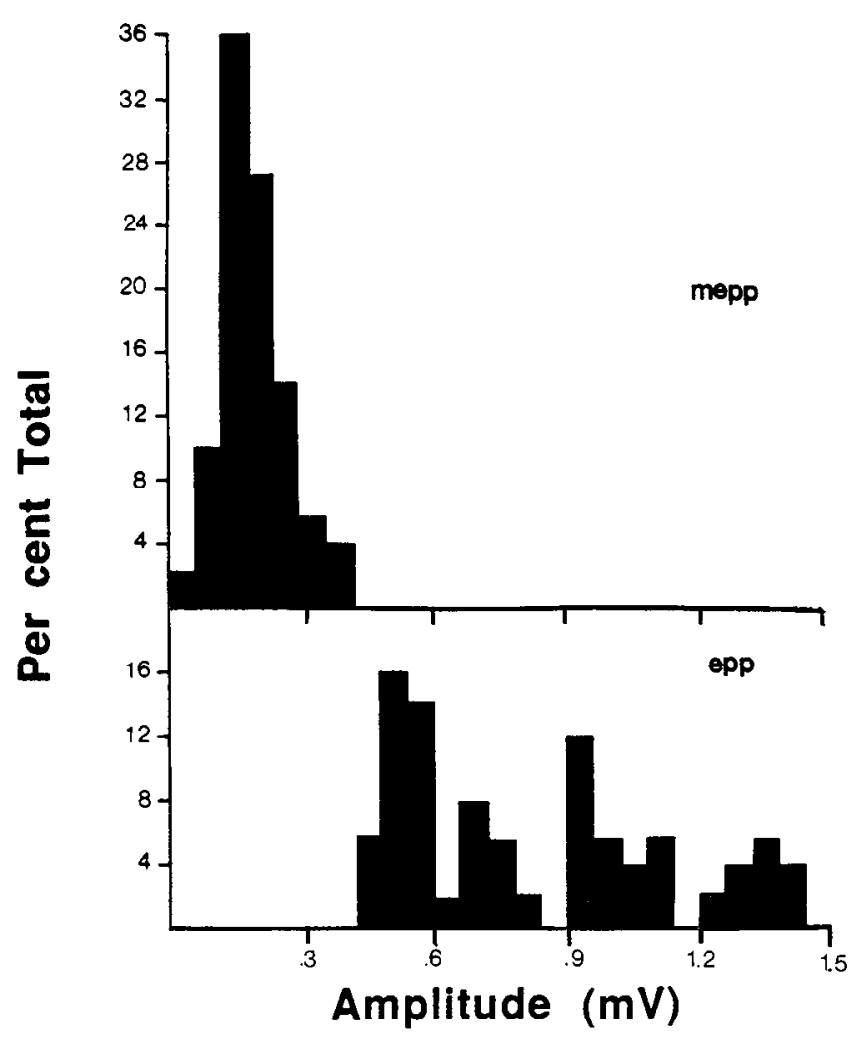

Figure 6. Amplitude histograms of miniature endplate potential (mepp) and evoked endplate potential (epp) distributions recorded at a representative junction of an old mouse $60 \mathrm{~d}$ after partial denervation. The mean mepp amplitude was $0.19 \mathrm{mV}$ and the mean epp amplitude was $0.60 \mathrm{mV}$.

trophy with decreased input resistance, because hypertrophic fibers ( $>45 \mu \mathrm{m}$ width) comprised only $13 \%$ of the population in young muscle at $60 \mathrm{~d}$, and only 6 and $12 \%$ of the population in old muscle at 60 and $120 \mathrm{~d}$, respectively (Fig. 2 in Jacob and Robbins, 1990). In summary, it appears that the reduced mepp amplitudes in sprouted junctions reflect a population of vesicles different from that which is released by nerve stimulation.

As in neuromuscular development (Dennis, 1981), a lower mepp frequency $60 \mathrm{~d}$ after partial denervation was associated with presumed sprouted terminals. In young animals, this reduction in mepp frequency (33\%) was large compared to the decrease in nerve terminal size at $60 \mathrm{~d}(\sim 14 \%$; Jacob and Robbins, 1990), indicating fewer release sites per nerve terminal length, or perhaps a lower internal calcium concentration. However, in partially denervated muscle in old mice, decrease in size of sprouted terminals, which was often profound (Jacob and Robbins, 1990), may account for lower mepp frequency.

\section{Latency and preterminal innervation}

Reductions in conduction velocity are characteristic of regenerating (Sanders and Whitteridge, 1946; Cragg and Thomas, 1964) or growing axons, due to reduced axon diameter, thinner myelin sheaths, and shorter internodal distances (Dennis and Miledi, 1974; Dennis, 1981). Correlative morphological data (Jacob and Robbins, 1990) indicate that similar mechanisms account for the long latencies in partially denervated muscles. The strong association at $30 \mathrm{~d}$ (young mice) and at 60 and 120 $\mathrm{d}$ (old mice) between long latency and low mepp frequency and low quantal content reinforces the view that most long-latency
Table 1. Relation between changes in median estimated quantal content $\left(1 / C V^{2}\right)$ and endplate potential amplitude before and after partial denervation ${ }^{a}$

\begin{tabular}{|c|c|c|c|c|c|c|}
\hline \multirow{2}{*}{$\begin{array}{l}\text { Days after } \\
\text { partial } \\
\text { denervation }\end{array}$} & \multicolumn{3}{|c|}{ Young } & \multicolumn{3}{|l|}{ Old } \\
\hline & $\begin{array}{l}\text { Con- } \\
\text { trol }\end{array}$ & 60 & 120 & $\begin{array}{l}\text { Con- } \\
\text { trol }\end{array}$ & 60 & 120 \\
\hline $1 / C V^{2}$ & 1.67 & 1.12 & 1.12 & 2.12 & 0.87 & 1.12 \\
\hline $\begin{array}{l}\% \text { control } \\
\text { epp amplitude }\end{array}$ & - & 67 & 67 & - & 41 & 52 \\
\hline$(\mathrm{mV})$ & 0.72 & 0.43 & 0.43 & 1.02 & 0.45 & 0.45 \\
\hline$\%$ control & - & 60 & 60 & - & 44 & 44 \\
\hline
\end{tabular}

${ }^{a}$ Each group of data is from 23-29 fibers. Except for days after operation, all data are median values.

junctions were sprouted. The striking persistence of a prolonged latency in about $60 \%$ of fibers at $120 \mathrm{~d}$ after operation in old mice (but not in young), i.e., in most of the reinnervated junctions, suggests there was negligible maturation of preterminal axons even though collateral reinnervation was functional.

\section{Transmitter release after partial denervation}

Thirty days after partial denervation, no functional sprouting had taken place; i.e., indirect twitch tensions were simply those expected from the observed loss of $70 \%$ of the motor axons. Therefore, at these times, comparison of twitch strength in normal vs low $\mathrm{Ca} /$ high $\mathrm{Mg}$ Krebs assayed the relative safety factor of the original remaining nerve terminals with little contamination by newly regenerated terminals. As expected, at 10 and $30 \mathrm{~d}$ after partial denervation in young mouse muscle, the safety factor of the original terminals was unchanged, even though collateral sprouting had begun (Robbins, unpublished). Surprisingly, in old muscle, the remaining terminals showed a reduced safety factor at these times. Thus, transmitter release of original intact terminals in old mice apparently decreased during collateral sprouting but before sprouts became functional. By 60 and $120 \mathrm{~d}$, however, intraccllular recording showed that presumed original nondenervated terminals (with short latency) released transmitter as in control junctions. Nonetheless, decreased mepp amplitude persisted in these short-latency junctions at $120 \mathrm{~d}$-another indicator of a physiological change distributed over both sprouted and original synapses.

At 60 and $120 \mathrm{~d}$ after partial denervation in both young and old muscle, the reduced transmitter release of sprouted fibers served to decrease the safety factor of the whole muscle in low Ca solution, consistent with intracellular data indicating reduced quantal content. Nonetheless, while the relative change after partial denervation was especially pronounced in old muscle, the absolute values of quantal content (and of mepp amplitude and frequency) in partially denervated muscle were actually similar in young and old muscle, since the starting control values were greater in old muscle. The relative decline in total transmitter release per motor neuron in old mice was well correlated with the decline in synaptic volume (cf. discussion, Jacob and Robbins, 1990). Therefore, it is unlikely that regenerated junctions in old mice simply reverted to a release mechanism similar to that of regenerated junctions in young mice.

\section{Overview}

After partial denervation, physiological deficits in mepp amplitude and frequency, transmitter release, and especially latency 
Figure 7. Histogram of quantal content $\left(m=1 / C V^{2}\right)$ measured in low $\mathrm{Ca}^{2+}$ / high $\mathrm{Mg}^{2+}$ Krebs solution at indicated times after partial denervation. Data were from 10-29 fibers in 3-7 partially denervated mice. Other information as in Figure 4.

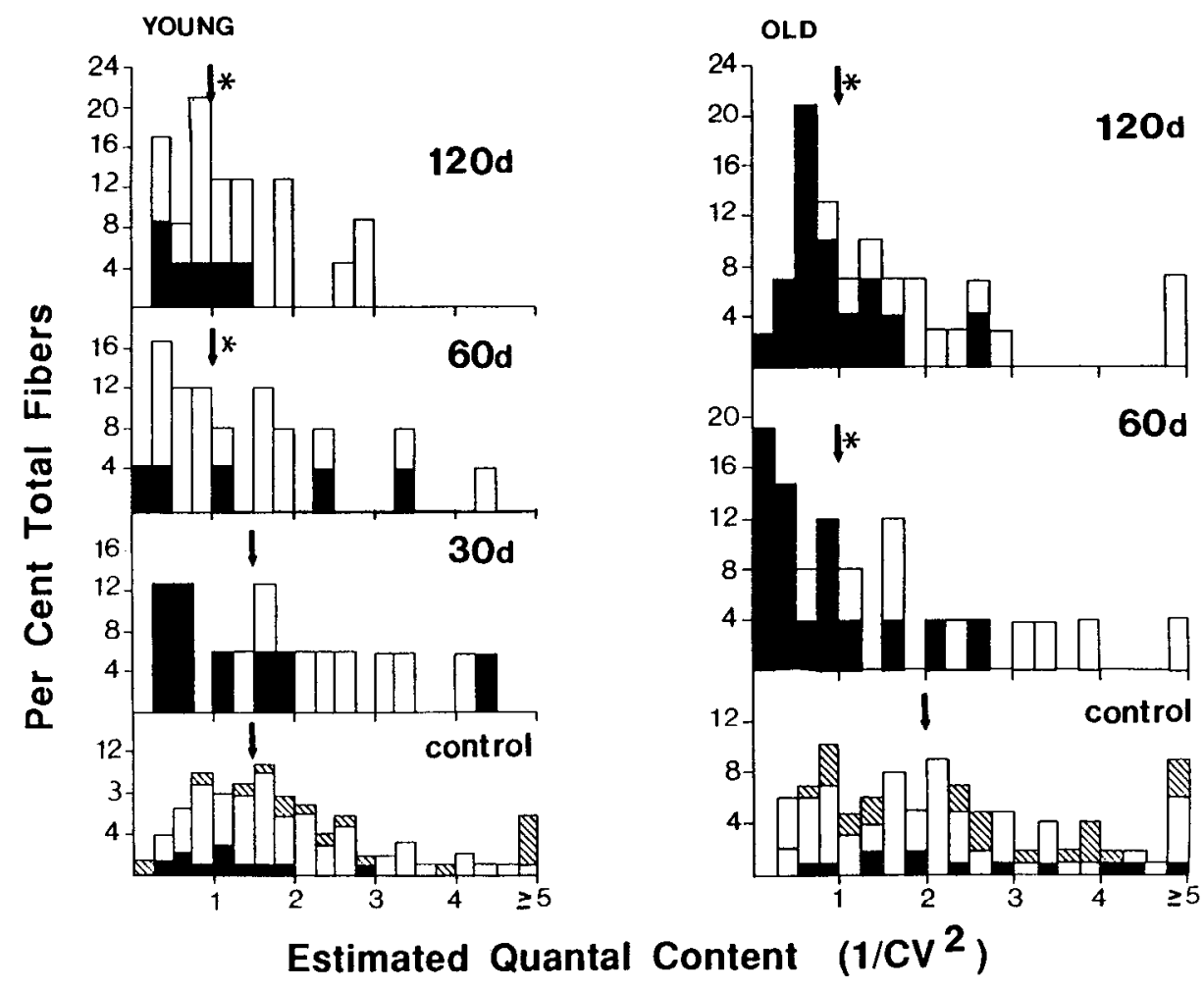

were greater and more prolonged in old than in young mice. In addition, in old mice, even the original nondenervated junctions showed deficits after expansion of motor unit size. These results indicate a reduced capacity of old motor neurons to adapt to, generate, and maintain an increased "field" of functional innervation. If still further expansion of the motor unit were required as in severely affected muscles in amyotrophic lateral sclcrosis (Wolhfart, 1957) or in postpoliomyelitis syndrome (Jubelt and Cashman, 1987), age differences in response to partial denervation could become clinically important.

In neurons of the central nervous system, small changes in depolarization or hyperpolarization or temporal summation critically affect circuit behavior (Rosenheimer and Smith, 1987). Therefore, if the changes in quantal release or latency described here in response to partial denervation also occurred after natural, age-related or stroke-induced loss of neurons in older individuals, the properties of both the original remaining synapses and those that sprouted would be sufficiently altered to have significant effects on brain function.

\section{References}

Banker BQ, Kelly SS, Robbins N (1983) Neuromuscular transmission and correlative morphology in young and old mice. J Physiol 239: 355-375.

Brown MC, Ironton R (1978a) Sprouting and regression of neuromuscular synapses in partially denervated mammalian muscle. $\mathrm{J}$ Physiol 278:325-348.

Brown MC, Ironton R (1978b) Suppression of motor nerve terminal sprouting in partially denervated mouse muscles. J Physiol 272:70P$71 P$.

Brown MC, Jansen JKS, Van Essen D (1976) Polyneuronal innervation of skeletal muscle in new-born rats and its elimination during maturation. J Physiol 261:387-422.

Cragg BG, Thomas PK (1964) The conduction velocity of regenerated peripheral nerve fibers. J Physiol 171:164-175.

Cull-Candy SG, Lundh H, Thesleff S (1976) Effects of botulinum toxin on neuromuscular transmission in the rat. J Physiol 260:177-203.
Curcio CA, Buell SJ, Coleman PD (1982) Morphology of the aging central nervous system: not all downhill. In: The aging motor system (Mortimer JA, Pirozollo FJ, Maletta GJ, ed), pp 7-35. New York: Praeger.

Del Castillo J, Katz B (1954) Quantal components of the endplate potential. J Physiol 124:560-573.

Dennis MJ (1981) Development of the neuromuscular junction: inductive interactions between cells. Annu Rev Neurosci 4:43-68.

Dennis MJ, Miledi R (1974) Non-transmitting neuromuscular junctions during an early stage of endplate reinnervation. J Physiol 239: 553-570.

Fahim MA, Robbins N (1982) Ultrastructural studies of young and old mouse neuromuscular junctions. J Neurocytol 11:641-656.

Grinnell AD, Herrera AA (1980) Physiological regulation of synaptic effectiveness at frog neuromuscular junctions. J Physiol 307:301-317.

Grinnell AD, Trussell LO (1983) Synaptic strength as a function of motor unit size in the normal frog sartorius. J Physiol 238:221-241.

Herrera AA, Grinnell AD (1981) Transmitter release from motor nerve terminals depends on motor unit size. Nature 287:649-651.

Jacob JM, Robbins N (1990) Age differences in morphology of reinnervation of partially denervated mouse muscle. J Neurosci 10:15301540.

Jubelt B, Cashman NR (1987) Neurologic manifestations of the postpolio syndrome. Crit Rev Neurobiol 3:199-220.

Kelly SS (1978) The effects of age on neuromuscular transmission. J Physiol 274:51-63.

Kelly SS, Robbins N (1983) Progression of age changes in synaptic transmission at mouse neuromuscular junctions. J Physiol 343:375383.

Kelly SS, Robbins N (1984) Bimodal miniature endplate potentials in adult mouse neuromuscular junctions. J Physiol 346:353-363.

Kelly SS, Robbins N (1987) Statistics of neuromuscular transmitter release in young and old mouse muscle. J Physiol 385:507-516.

Komiya Y (1980) Slowing with age of rate of slow axonal flow in bifurcating axons of rat dorsal root ganglion cells. Brain Res 183:477488.

McMartin DN, O'Connor JA Jr (1979) Effect of age on axoplasmic transport of cholinesterase in rat sciatic nerves. Mech Age Dev 10: 241-248.

McWilliams JR (1988) Age-related declines in anatomical plasticity and axonal sprouting. In: Neural plasticity: a lifespan approach (Petit TL, Ivy GO, eds), pp 329-349. New York: Liss. 
Rochel S, Robbins N (1988) The effect of partial denervation and terminal field expansion on neuromuscular transmitter release and nerve terminal structure. J Neurosci 8:332-338.

Rosenheimer JL, Smith DO (1987) Analysis of a neurite outgrowth factor from denervated muscle extract which exhibits an age-related increase in potency in vitro. Soc Neurosci Abstr 13(Pt 3):1613.

Sanders FK, Whitteridge D (1946) Conduction velocity and myelin thickness in regenerating nerve fibers. J Physiol 105:152-174.

Scheff SW, Anderson K, DeKovsky ST (1984) Morphological aspects of brain damage in aging. In: Aging and recovery of function in the central nervous system (ScheffSW, ed), pp 57-85. New York: Plenum.
Slack JR, Hopkins WG (1982) Neuromuscular transmission at terminals of sprouted mammalian motor terminals. Brain Res 237:121135.

Thompson W, Jansen JKS (1977) The extent of sprouting of remaining motor units in partly denervated immature and adult rat soleus muscle. Neuroscience 2:523-535.

Wohlfart G (1957) Collateral regeneration from residual motor nerve fibers in amyotrophic lateral sclerosis. Neurology 7:124-134. 